\title{
Postoperative Compression with Adhesive Tape Strips for the Auricular Pseudocyst Management
}

\author{
Jeong Hwan Choi, MD and Seung Ho Kim, MD \\ Department of Otorhinolaryngology-Head and Neck Surgery, Sanggye Paik Hospital, \\ College of Medicine, Inje University, Seoul, Korea
}

\begin{abstract}
- ABSTRACT -
Auricular pseudocyst (APC) also known as idiopathic cystic chondromalacia, is a very uncommon cystic lesion at the auricle. Because of rarity of APC, it can be misdiagnosed or delayed in treatment. Those mismanagements could leave disfiguring auricular deformities. APC typically presents as a unilateral asymptomatic swelling in the upper part of auricle in males. Intracartilagenous cystic degeneration is characteristic histologic findings. Managements aim at removal the cyst without relapsing and restoring the original shape of the auricle. However, until now trials have not been perfectly satisfied in terms of recurrence. In this article we report two cases of APC that was successfully treated by surgery - specifically, excision of the anterior or both leaves of cystic wall with adhesive surgical tape compression - and yielded confident results with good cosmesis. There were no recurrence of follow-up after excision. (J Clinical Otolaryngol 2019;30:237-242)
\end{abstract}

KEY WORDS : Ear · Ear auricle $\cdot$ Cyst.

\section{Introduction}

Engel used "pseudocyst" of the auricle (APC) to report the intracartilageneous cyst without epithelial lining. ${ }^{1,2)}$ APC also known as endochondral APC and idiopathic cystic chondromalacia. ${ }^{3)}$

APC is characterized by an asymptomatic unilateral benign cystic lesion in the triangular or scaphoid fossa of the auricle. ${ }^{4-6)}$ The APC is a very rare entity of the auricle and exclusively found in male., ${ }^{5,7,8)}$

As "idiopathic" implies, APC has an unknown etiology of cyst formation in the auricular cartilage so far. However, it may be related to an embryological or developmental malformation. ${ }^{9)}$ Minor repetitive trauma from various sources such as wood pillows, ${ }^{10,11)}$ mo-

논문접수일: 2019년 9월 20일 논문수정일 : 2019년 10월 16일

심사완료일 : 2019년 11월 22일

교신저자 : 최정환, 01757 서울 노원구 동일로 1342

인제대학교 의과대학 상계백병원 이비인후과학교실

전화 : (02) 950-1104·전송 : (02) 935-6220

E-mail:choijh92@paik.ac.kr torcycle helmets $^{11)}$ or headphones, ${ }^{11)}$ and other causes of ear folding or repeated rubbing, all have been reported to trigger the cyst formation. ${ }^{5,10)}$ The presence of hemosiderin supports the trauma theory and it implies preceding leakage of blood from the neighboring vessels as a result of trauma. ${ }^{11)}$ Those insults have been reported to lead to the release of lysosomal enzymes resulting in cartilaginous autolysis and degeneration with separation, fibrosis, progressive dilatation, and subsequent cyst formation. ${ }^{1)}$ However, lysozyme has not been isolated in later studies. ${ }^{6,10)}$ This intracartilaginous cavity without epithelial lining, is filled with serous fluid. ${ }^{7}$ The concentrations of protein, albumin, glucose, and cholesterol was similar to those of them in serum. ${ }^{6,9)}$

Repeated trauma can initiate a leakage of glycosaminoglycans, which, forming as intracartilagenous microcysts, coalesce to join a larger cyst. ${ }^{10)}$ However, there are many reports without apparent preceding trauma history. Detailed questioning and thoroughly investigation should be applied to uncover it. ${ }^{10)}$ 
Various nonsurgical treatments for ACPs are described in the literature, including aspiration and intralesional injection of steroids and other sclerosing agents such as trichloroacetic acid with the aim of inducing fibrosis. ${ }^{12)}$ Variable surgical procedures have also been used to reduce the high recurrence rate after performance of less invasive treatments. ${ }^{4}$

\section{Case Report}

\section{Case 1}

A 26-year-old man was referred to our clinic for the right auricular mass in several years. He denied any history of preceding trauma. Transfer report said trials of several aspirations were unsuccessful. A $0.5 \mathrm{~cm}$ diameter firm and slightly fluctuating mass was palpated at the scapha of the right auricle. It was palpated at anterior and posterior surfaces of the auricle (Fig. 1). The helix also slightly protruded outward by the mass. The needle aspiration was tried, but until reaching the hard part, only a dry tap was obtained. The impression of organized subpericondrial hematoma, APC, or chondroma was made. After obtaining the consent of possible floopy ear, auricular mass excision via posterior approach was planned. The entire auricle was sterilized with betadine and drapped for surgery. After local injection with $2 \%$ lidocaine and $1: 80,000$ epinephrine around mass including anterior and posterior auricular skin. A helical incision of the posterior auricular skin was made. Then, the skin flap was elevated beyond the boundary of the mass. The mass was located within the cartilage. When the cut through the posterior cartilage was performed, serous fluid was released. The posterior cartilage leaf of the cyst was excised along the margin and the borders were smoothened. However, anterior and helical bulging were still remained. So, remaining anterior cartilage leaf was also excised. The skin was repositioned to its original site and closed with simple 5-0 Nylone sutures. To prevent hematoma, we applied several adhesive surgical tape strips (ASTs) (Nexcare Steri-Strips, 3M, MN, USA) applied to compress the raised skin flap. No ad-

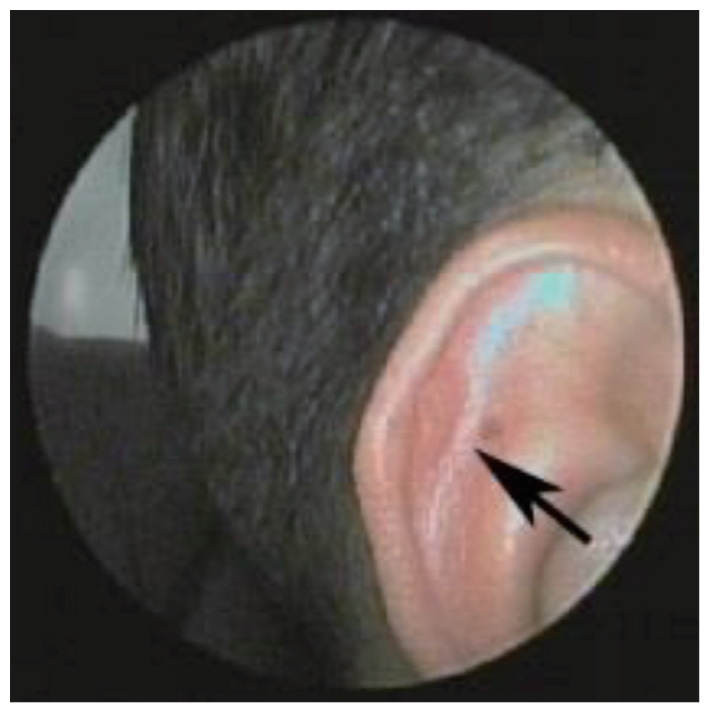

Fig. 1. A $0.5 \mathrm{~cm}$-diameter firm and slightly fluctuating mass (arrow) is palpated at the scapha of the right auricle. The helix also slightly protrudes outward by the mass.

ditional external dressing was required. The sutures were removed after one week. At that time, ASTs were changed new one and reapplied firmly. After 2 weeks, remaining strips were gently removed. Histological findings were compatible with an APC without an epithelial lining (Fig. 2). There was no recurrence with fine cosmesis at 8-month of follow-up after excision (Fig. 3).

\section{Case 2}

A 60 -year-old man presented with a 4-year history of a slow growing mass of the right ear. He could not recall any preceding trauma. Physical examination revealed a $1.4 \times 1 \mathrm{~cm}$ sized firm mass in the scaphoid fossa. The overlying skin was unremarkable (Fig. 4). The trial of needle aspiration was unsuccessful. The differential diagnosis included subperichondrial organized hematoma, APC, and relapsing polychondritis.

The patient wanted to excision for diagnosis. The entire auricle was sterilized with betadine and drapped for surgery. After injection with $2 \%$ lidocaine and 1 : 80,000 epinephrine around mass, a linear incision was made just above the mass. Then, the skin flap was elevated beyond the boundary of the mass. A tangential 

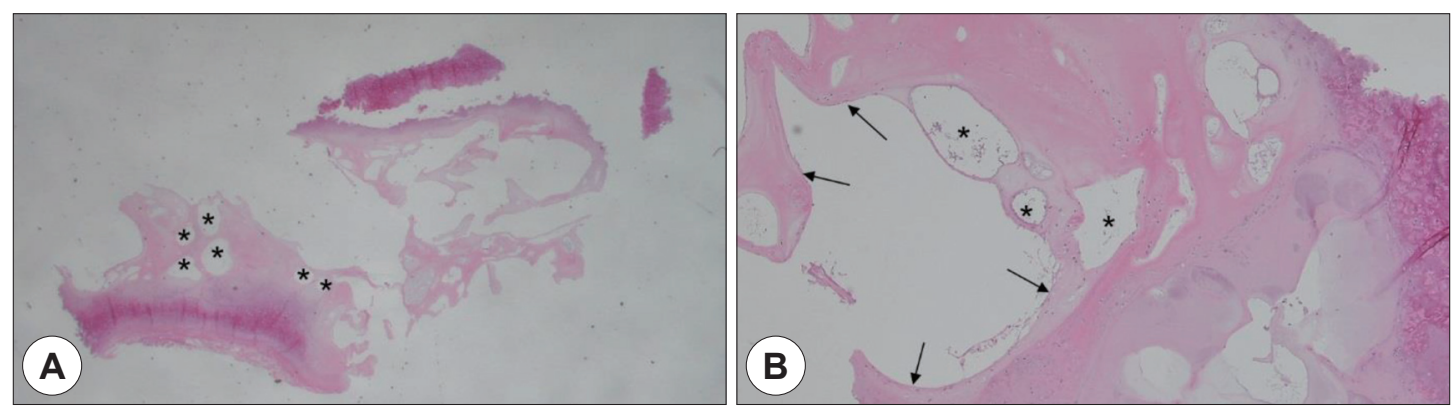

Fig. 2. Histological findings is compatible with an auricular pseudocyst. There are intracartilagenous multiple microcysts (asterisks), coalesce to join a larger cyst (A). The cyst wall does not have any epithelium (arrows)(B).

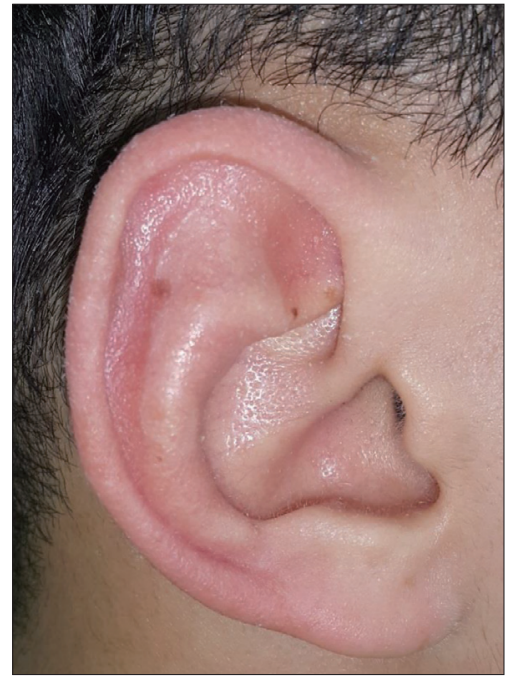

Fig. 3. There is no recurrence with fine cosmesis at 8-month of follow-up after excision. The protruded outline of helix restores original contour.

incision was made around mass through the anterior leaf of cartilage and perichondrium. The release of the straw-colored fluid was observed. The anterior wall of perichondrium and cartilage leaf of the cyst were excised along the margin and the borders were smoothened. Thorough curettage of the granulation above posterior cartilagenous leaf of the cyst was performed. Meticulous hemostasis was followed to prevent hematoma formation. The skin and anterior pericondrial flap was repositioned above the remaining posterior cartilageneous leaf and closed with simple 5-0 Nylone sutures. Postoperative compression was done as same as previous case one (Fig. 5). Histological find- ings were compatible with an APC without an epithelial lining. There also were focal destruction of the cartilage and fibrosis in surround tissue (Fig. 6). There was no recurrence of the lesion with good cosmesis over a follow-up period of one year.

\section{Discussion}

The differential diagnosis of soft swellings of the auricle includes benign cysts such as epidermal or dermoid cysts, auricular seroma, subperichondrial hematoma, and APC, or ; inflammatory lesions such as relapsing polychondritis, and chondrodermatitis nodularis helicis; and benign tumors such as chondromas, trichilemmoma, and rarely angiomas. ${ }^{13)}$ Interestingly many reports of APC might misdiagnosed seroma. ${ }^{13)}$ Many reports did not specify which plane the fluid was.

Characteristic histological positions and features are main points of differentiation. The lesion within the cartilage is considered as APC. On the other hand, epidermal or dermoid cyst are located at the subcutenous layer above the perichondrium. Otohematoma and auricular seroma are located subperichondrial and above the cartilage (Fig. 7). ${ }^{9)}$ There are characteristic clinical features such as painful chondrodermatitis nodularis helicis, diffuse reddish relapsing polychondritis, and well aspirated subperichondrial hematoma.

Managements aim at removal the cyst without relapsing and restoring the shape of the auricle. Despite variable treatment modalities has been designed, the treatment of choice cannot be decided so far because 


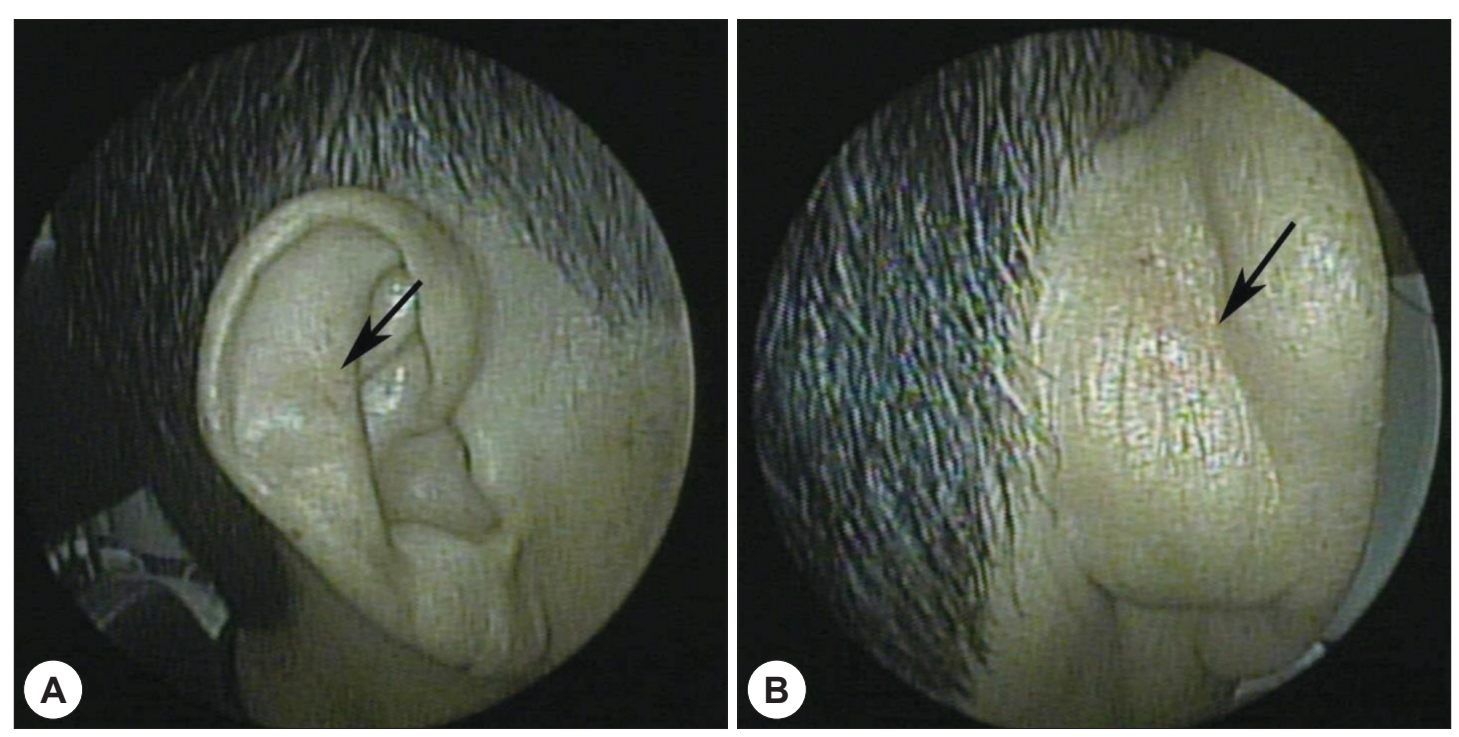

Fig. 4. Physical examination reveals a $1.4 \times 1 \mathrm{~cm}$ sized firm mass (arrow) in the scaphoid fossa. It was palpated at anterior (A) and posterior surfaces (B) of the auricle. Overlying skin is unremarkable.

of the high recurrence rate, which made APC is very annoying for the clinician.

Simple observation has not been recommended, untreated APCs used to induce progressive hardening or subsequently destruction or deformity of cartilage. ${ }^{11)}$

Simple aspiration of cystic fluid tends to reaccumulation. ${ }^{14)}$ Therefore, aspiration was considered a diagnostic procedure rather than a therapeutic one. ${ }^{15)}$ Aspiration followed by compression has been designed to decrease the recurrence rate.

Aspiration and additional intracystic injection of corticosteroid $^{16)}$ or sclerosing agent such as minocycline, $50 \%$ trichloro acetic acid, ${ }^{12)}$ bleomycin, fibrin glue ${ }^{17)}$ or iodine tincture also have been applied with reports of variable success rate.

Intralesional steroid injections have the risk of some complications such as a skin pigmentation, atrophy, auricular deformity, and a high recurrence rate. ${ }^{11)}$ Systemic corticosteroids also failed to subside.

The cystic fluid is gradually originated from the perichondrium in the anterior wall. ${ }^{18)}$ Therefore, simple aspiration or inducing sclerosis cannot prevent reaccumulation, since the remained perichondrium can reproduce the fluid. The treatment should focus to remove

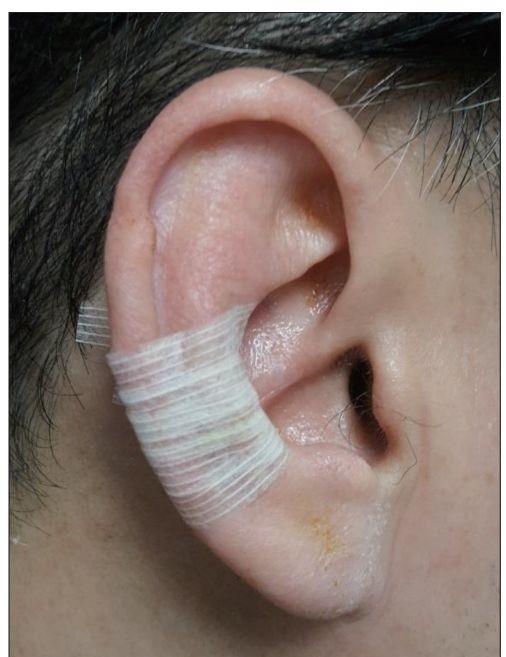

Fig. 5. After the excision of the cartilage leafs of the auricular pseudocyst, several adhesive surgical tape strips applied and compress the raised skin flap.

the anterior perichondrium.

Variable surgical approaches have been applied for treating the APC. Incision and drainage, ${ }^{19)}$ insertion the drain $^{5)}$ and punching the inferior border of the $\mathrm{APC}^{2)}$ were reported. To reduce recurrence, following compressive dressing has been proposed. Besides traditional contour dressing, variable compression materi- 

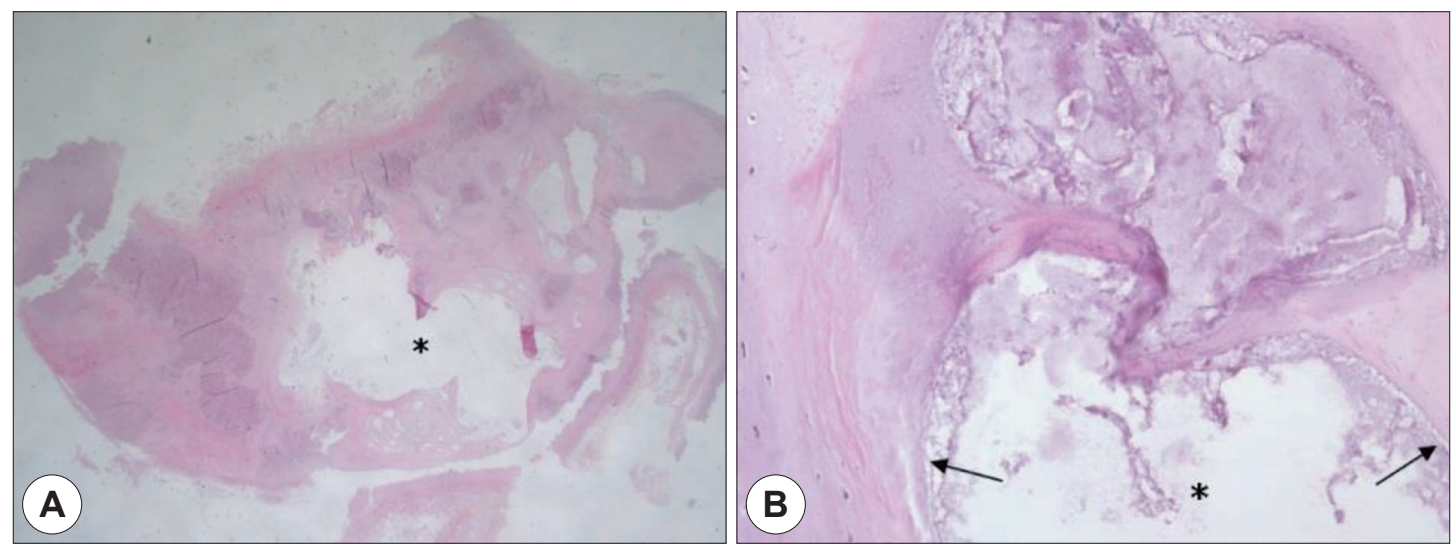

Fig. 6. Histological findings are compatible with an auricular pseudocyst (asterisk)(A). The cyst does not have any epithelial lining (arrows). There also were focal destruction of the cartilage and fibrosis in surround tissue (B).

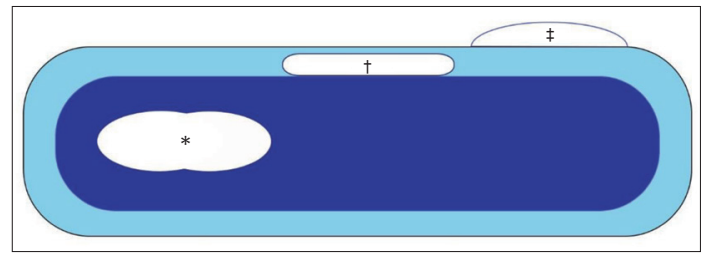

Fig. 7. Characteristic histological positions and features are main points of differentiation in the auricular cystic lesions. The lesion within the cartilage (blue) is considered as auricular pseudocyst (asterisk). On the other hand, otohematoma and auricular seroma $(\dagger)$ are located subperichondrial and above the cartilage (blue). Epidermal or dermoid cyst $(\ddagger)$ are located at the subcutenous layer above the perichondrium (sky blue).

al such as bolstered pressure sutures, ${ }^{20)}$ plaster of Paris casts, ${ }^{8)}$ clip, ${ }^{4,16)}$ and button ${ }^{15)}$ have been applied with variable success rates. However, problems of APC recurrences, prolonged application and deformed cartilage still remained.

To overcome this issue, more invasive procedures of deroofing of the APC was introduced. ${ }^{10)}$ After removing the anterior cartilagenous leaf, curettage of the posterior wall is performed, followed by the compression dressing. Recurrence could be reduced if the anterior degenerated cartilage of the APC can be removed completely. However, the posterior leaf should be preserved to prevent floppy ear deformity. ${ }^{1,10)}$ But extirpation of cyst is inevitable in some case like our second case to restore original shape of auricle. Surgical deroofing of the APC was reported with no recur- rence and good cosmesis in most cases. ${ }^{10)}$ Original contour dressings ${ }^{10)}$ was modified to use buttoning as a compression method without recurrence. ${ }^{15)}$ button bolsters ${ }^{14)}$ were not convenient to be resized. Therefore, the use of AST is very convenient to apply variable length. Customized AST with suitable lengths or widths could have definite effects on the auricular compression.

We use the adhesive surgical tape strips in the postoperative compression of APC. We prefer excision of the anterior leaf of the APC, leaving intact posterior leaf, followed by AST compression of the wound.

\section{Conclusion}

For the clinician, APC could be very annoying in terms of recurrence. We prefer excision of the anterior leaf of the APC, leaving intact posterior leaf as far as possible, followed by AST compression of the wound. This method is better for cosmesis and patient's comfort without prolonged bulky pressure compression.

\section{REFERENCES}

1) Engel D. Pseudocysts of the auricle in Chinese. Arch Otolaryngol 1966;83(3):197-202.

2) Paul AY, Pak HS, Welch ML, Toner CB, Yeager J. Pseudocyst of the auricle: diagnosis and management with a punch biopsy. J Am Acad Dermatol 2001;45(6 Suppl):S230-2.

3) Heffner DK, Hyams VJ. Cystic chondromalacia (endochon- 
dral pseudocyst) of the auricle. Arch Pathol Lab Med 1986; 110(8):740-3.

4) Salgado CJ, Hardy JE, Mardini S, Dockery JM, Matthews MS. Treatment of auricular pseudocyst with aspiration and local pressure. J Plast Reconstr Aesthet Surg 2006;59(12): 1450-2.

5) Zhu L, Wang X. Histological examination of the auricular cartilage and pseudocyst of the auricle. J Laryngol Otol 1992;106(2):103-4.

6) Cohen PR, Grossman ME. Pseudocyst of the auricle. Case report and world literature review. Arch Otolaryngol Head Neck Surg 1990;116(10):1202-4.

7) Ichioka S, Yamada A, Ueda K, Harii K. Pseudocyst of the auricle: case reports and its biochemical characteristics. Ann Plast Surg 1993;31(5):471-4.

8) Hegde R, Bhargava S, Bhargava KB. Pseudocyst of the auricle: a new method of treatment. J Laryngol Otol 1996;110 (8):767-9.

9) Lee JA, Panarese A. Endochondral pseudocyst of the auricle. J Clin Pathol 1994;47(10):961-3.

10) Choi S, Lam KH, Chan KW, Ghadially FN, Ng AS. Endochondral pseudocyst of the auricle in Chinese. Arch Otolaryngol 1984;110(12):792-6.

11) Glamb R, Kim R. Pseudocyst of the auricle. J Am Acad Dermatol 1984;11(1):58-63.

12) Cohen PR, Katz BE. Pseudocyst of the auricle: successful treatment with intracartilaginous trichloroacetic acid and button bolsters. J Dermatol Surg Oncol 1991;17(3):255-8.

13) Kopera D, Soyer HP, Smolle J, Kerl H. "Pseudocyst of the auricle", othematoma and otoseroma: three faces of the same coin? Eur J Dermatol 2000;10(6):451-4.

14) Kanotra SP, Lateef M. Pseudocyst of pinna: a recurrencefree approach. Am J Otolaryngol 2009;30(2):73-9.

15) Lim CM, Goh YH, Chao SS, Lynne L. Pseudocyst of the auricle. Laryngoscope 2002;112(11):2033-6.

16) Kim TY, Kim DH, Yoon MS. Treatment of a recurrent auricular pseudocyst with intralesional steroid injection and clip compression dressing. Dermatol Surg 2009;35(2):245-7.

17) Tuncer S, Basterzi Y, Yavuzer R. Recurrent auricular pseudocyst: a new treatment recommendation with curettage and fibrin glue. Dermatol Surg 2003;29(10):1080-3.

18) Zhang XT, Sun B, Ling Y, Zhang Y, Zhang Q, Kang AJ, et al. [Investigation of clinical pathology and treatments on the auricle pseudocyst]. Zhonghua Er Bi Yan Hou Tou Jing Wai Ke Za Zhi 2010;45(8):640-4.

19) Lim CM, Goh YH, Chao SS, Lim LH, Lim L. Pseudocyst of the auricle: a histologic perspective. Laryngoscope 2004; 114(7):1281-4.

20) Ophir D, Marshak G. Needle aspiration and pressure sutures for auricular pseudocyst. Plast Reconstr Surg 1991;87 (4):783-4. 